\title{
XXIII. The measurement of cyclically varying temperature
}

\author{
Henry F. W. Burstall M.A. A.M.I.C.E.
}

To cite this article: Henry F. W. Burstall M.A. A.M.I.C.E. (1895) XXIII. The measurement of cyclically varying temperature, Philosophical Magazine Series 5, 40:244, 282-297, DOI: 10.1080/14786449508620772

To link to this article: http://dx.doi.org/10.1080/14786449508620772

曲 Published online: 08 May 2009.

Submit your article to this journal $[\pi$

Џ Article views: 2

Q View related articles $\asymp$ 
of the $\tau^{*}$, and those, on the other hand, of the $\tau^{* *}$, may possibly be identical. In fact, it is found that the values of $\tau^{*}$ are practically identical for benzene, ehloroform, and carbon tetrachloride, being equal to about $\cdot 70$. For water, aceton, and carbon bisulphide $\tau^{*}$ seems to be somewhat higher, whereas for ether it is much lower : such results, however, do not seem to deserve much confidence. Still, if we assume for a moment $\tau^{*}$ for hydrogen to be $\cdot 75$ say, we find $-242^{\circ}$ for $T^{*}$; and then the second point of inversion ought to lie somewhere between that temperature and the critical, that is, $-232^{\circ}$.

XXIII. The Measurement of Cyclically Varying Temperature. By Henry F. W. Burstall, M.A., A.M.I.C.E.*

\section{[Plates I. \& II.]}

I HAVE been engaged since the latter end of 1892 in attempting the measurement of the temperatures reached in the cylinder of a gas-engine, and the following paper embodies the results which I have obtained.

So far as I am aware no experiments on this subject have been previously published; such attempts as have been made have failed from the want of a sufficiently sensitive thermometer. The platinum resistance-thermometer has, however, proved to have the required sensitiveness, and I shall devote this paper to the description of one of its forms which I have found suitable for the measurement of cyclically varying temperature.

The direct determination of the temperature in the cylinder clears the field for more complete discussion of the theory of the gas-engine, but as I would rather treat the experiments which I have already made as preliminary only, I will not enter into any discussion on this point in the present paper.

I had hoped during this work to have had the collaboration of Prof. Kapper, but unfortunately, owing to the pressure of other work, be was unable to devote the necessary time to these researches. I wish to take this opportunity of thanking: him for putting at my disposal the experimental gas-engine at King's College, and also for many valuable suggestions he has made during the course of the work.

The engine used is an Otto cycle-engine. This cycle, which is that now most generally used in internal combustion-engines, is completed in four strokes of the piston.

* Comniunicated by the Physical Society : read June 14, 1895. 
During the first stroke a charge of mixed air and combustible gas is drawn into the cylinder by the forward motion of the piston, the air- and gas-valves are now closed automatically, and the piston, on its second stroke, compresses the mixture, nearly adiabatically ${ }^{*}$, into the clearance space. This space forms a prolongation of the working cylinder, and has a capacity of about 45 per cent. of the volume swept through by the piston. The pressure reached at the end of the compression stroke is thus about four atmospheres. At the commencement of the third stroke communication is opened to the ignition-tube; the mixture then explodes, and the pressure rises to about fifteen atmospheres. The piston moves forward and the pressure falls, as the heated gases expand, until it is about three and a half atmospheres. This takes place just before the end of the stroke, and at this point the exhaust-valve opens. During the fourth stroke the products are discharged from the cylinder.

In order to measure the extremely high temperatures which were known certainly to be reached during such a cycle, some special form of thermometer had to be employed : not only is the temperature high, but the pressures to be dealt with are such as to destroy any thermometer not constructed of materials capable of resisting great mechanical stresses. It appeared to me that the platinum resistance-thermometer, which has been brought to such perfection by Callendar and Griffiths, and whose constants can be determined with such a high degree of accuracy, gave the greatest promise of success.

The general form and construction of such thermometers are now so well known, that I will only describe the special form which I have employed to fulfil the following conditions, which had to be satisfied in this particular case :-

(i.) The thermal capacity must be small, as the variations of temperature are extremely rapid. A whole stroke of this engine is completed in less than one fourth of a second; during this time the temperature varies about $500^{\circ} \mathrm{C}$, and as the temperature has to be measured at any fraction of the stroke, a lag of 0.01 second corresponds to one tenth of the stroke of the piston.

(ii.) The body of the thermometer must be made of some strong material such as iron or steel, as the impulsive pressures would immediately destroy any weaker material.

* During compression the pressure and volume are approximately connected by the relation $p v^{1 \cdot 3}=$ constant. 
(iii.) From the nature of the thermometer chosen, the leads must be well insulated from each other and from the body of the instrument, the insulating material being such as to stand high temperatures.

To fulfil all these conditions was by no means easy. In order to satisfy the first I was forced to employ a naked wire of small diameter, which obviously gives the minimum thermal capacity per unit of surface. I was fully aware that the whole of Callendar and Griffiths's work had been done on wires which were carefully shielded from the least contamination by means of an outer envelope; hence it might have been expected that a naked wire would prove unreliable, but I show later that, provided suitable precautions are taken, naked wires give satisfactory results, at any rate to the order of accuracy of my experiments.

The difficulties of obtaining the requisite mechanical strength, and at the same time good insulation, were very great; and nearly twelve months' work was expended before a satisfactory solution of the problem was obtained. The greater number of the earlier instruments were deficient in mechanical strength. In most laboratory experiments this is seldom of great importance; but this weakness invariably led to the thermometer being blown out of the engine after a few explosions, and the results were disastrous to the experiments.

\section{Description of the Thermometer. (Plate I. fig. 1.)}

The body of the thermometer consists of a seamless steel tube 15 inches long and $\frac{8}{4}$ inch ontside diameter; the outside of the tube is screwed from end to end with a fine thread. Working on this thread is a nut $N$, so arranged that the thermometer-wire can be immersed to any required depth in the gas-engine cylinder. For a distance of about one inch from one end, $A$, the tube is threaded in the interior and a small ring screwed in. Against this ring, which forms an internal collar, rests a circular slate block (C) pierced with four small holes through which the four leads pass. These leads are of platinum, 0.03 inch diameter and 4 inches long. About 1.5 inches from the end A small platinum collars are gold-soldered on to the leads; these prevent the leads from being blown out of the tube, by bearing against the slate block. In the stem of the thermometer the leads are of stout copper soldered with brass to the platinum leads and separated from each other by mica washers. After the leads have been put in position, a packing of alternate layers of asbestos and mica washers is placed on the slate block, as shown in the 

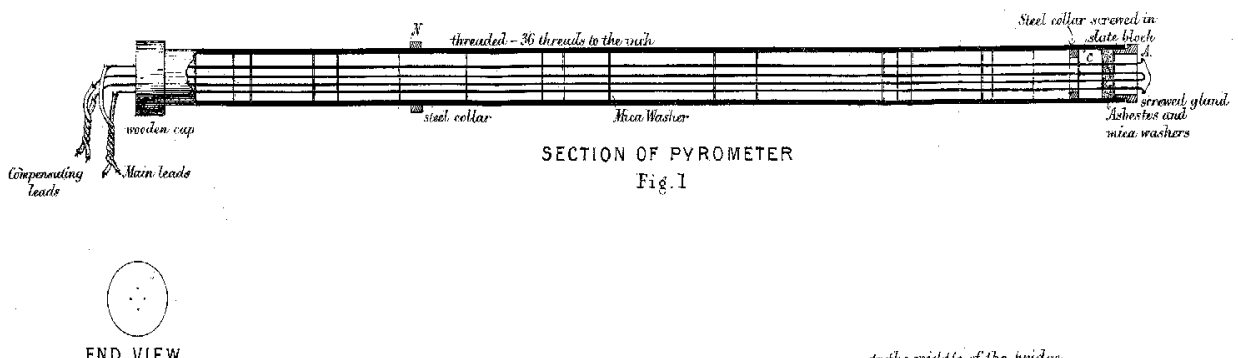

END VIEW.

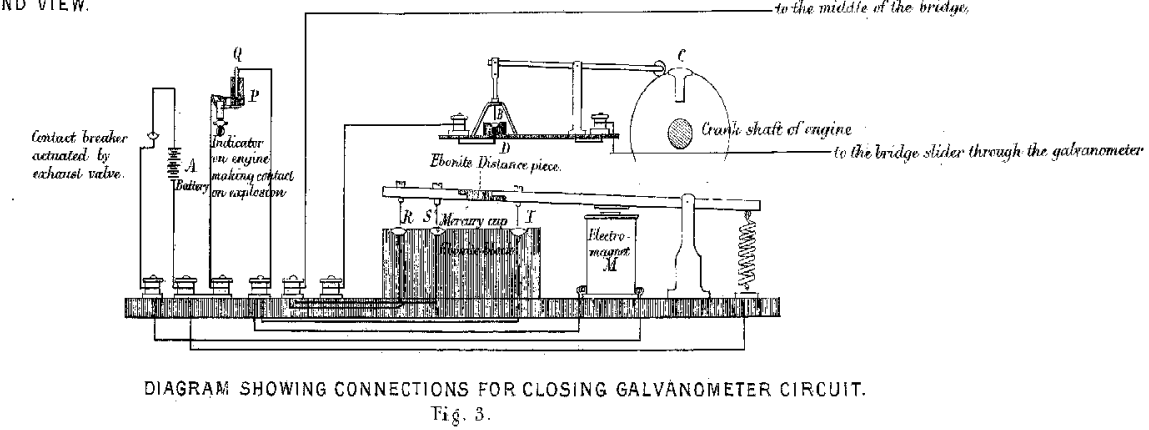

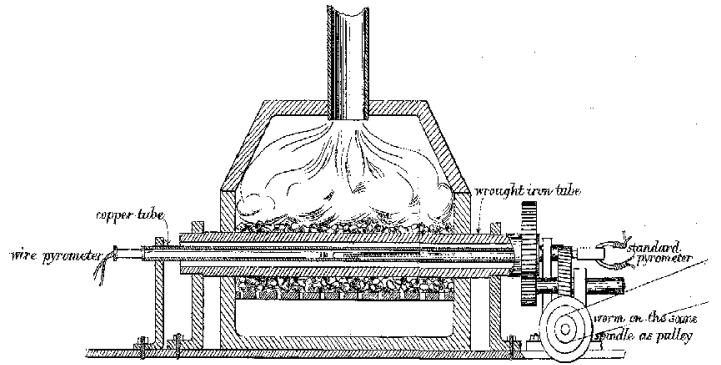

SECTION OF TUBE FURNACE SHOWING PYROMETERS IN POSITION

Fig. 4.

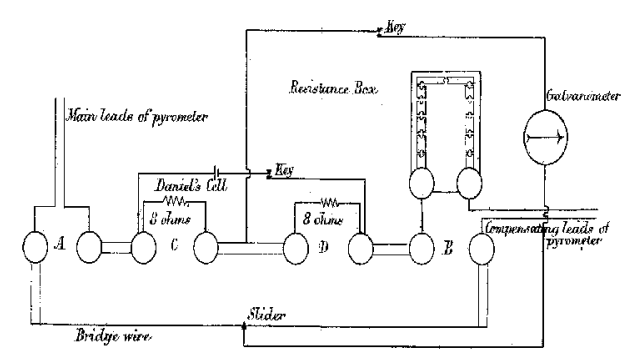

DIAGRAM OF BRIDGE CONNECTIONS 
figure, and by means of the serew-gland $D$ is forced into all the interstices-the instrument thus being made tight under the pressure. Four leads are used, two being joined by the measuring-wire, the other two being joined directly together*.

Description of the Resistance-Measuring Apparatus.

In order to readily eliminate the changes of resistance of the leads, an equal-arm slide-bridge was employed. The connexions are shown diagrammatically in fig. 2.

In the arm A are placed the main leads; in the opposite arm $\mathrm{B}$ are the compensating leads in series with the resistancebox. In the arms $\mathrm{C}$ and $\mathrm{D}$ are two carefully adjusted equal coils, each having a resistance of about 8 ohms. The bridgewire is of platinum-iridium, and is half a metre long; its resistance is $0.2980 \mathrm{ohm}$ at $15^{\circ} \mathrm{C}$. This wire was calibrated by Carey Foster's method, and, for the degree of accuracy required $(0.001 \mathrm{ohm})$, was found to be of sensibly equal resistance per unit length throughout.

The galvanometer, a very dead-beat astatic instrument, had a resistance of about $100 \mathrm{ohms}$. The magnet system and mirror were suspended by a quartz fibre 1.5 inches long, and was damped by a specially large mica damper very closely enclosed.

The scale was placed 4 feet from the mirror, so that a change of resistance of $0.0005 \mathrm{ohm}$ could be readily detected.

The resistance-box was an ordinary plug series box with platinoid coils. It was, in the first instance, calibrated by Mr. E. Wilson, of King's College; but after considerable use so much trouble was given and, indeed, so many experiments spoiled through the inefficiency of the plugs, that links, screwed up by a screwdriver, were substituted for them. Although the links are not so convenient to work with as the plugs, the results have been in every way satisfactory since this change. I then re-calibrated the box, and the two determinations were in fair agreement. Below I give a table of the values of the coils used during the experiments :-

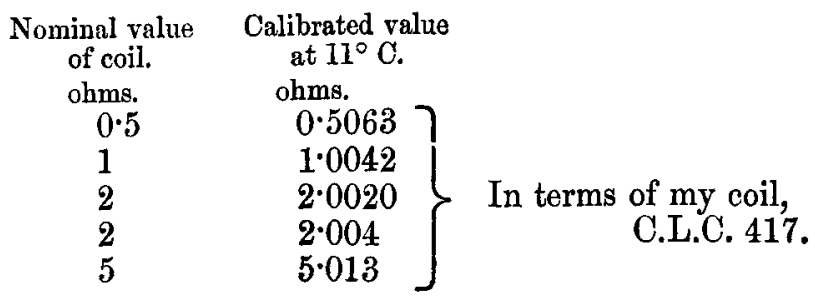

* For permission to use the compensators (the invention of Mr. Callendar), I am indebted to the Cambridge Scientific Instrument Company. 
As the working stroke in the Otto cycle only occurs once in four strokes of the piston, and as the temperature had to be measured at particular parts of that stroke, it was necessary that the galvanometer should only be in circuit at the right moment, otherwise the galvanometer swing would not give an indication of the true temperature of the wire. During each explosion stroke the measuring-wire goes through the whole cycle of temperature and, in order to secure a parti: cular epoch of this stroke, the following arrangement of contact makers (shown in fig. 3) was designed. The galvanometer circuit was broken in two places, one of which was made during every working stroke, and the other at a definite epoch at every revolution; thus the galvanometer circuit was only completely made at one definite point in every working stroke. At any required point in the stroke of the piston, contact is made every revolution by a cam (C) on the crankshaft of the engine lifting one end of a vibrating lever, depressing a wire (B), fixed to the other end, into a mercury cup $\mathrm{D}$, and thus making a galvanometer contact for a definite time (about $\frac{1}{2} 0$ of the stroke) at a certain fraction of the stroke. This, however, makes contact once every revolution, while the temperature is measured only during an explosion stroke. To ensure that the galvanometer circuit shall only be made during every working stroke, it is again broken and only made at the proper time by a relay. This relay is on a separate circuit which is completed by means of a steamengine indicator $(\mathrm{P})$, whose pencil is replaced by a metal point. During the compression and exhaust strokes the pencil bears on a boxwood cylinder, but when the explosion occurs the arm is forced upwards by the pressure and the pointer makes contact on a strip of brass $Q$, thus completing the relay circuit. The electromagnet is excited and the beam depressed, completing the galvanometer circuit through the mercury cups $R$ and $S$. As soon as the relay has moved through a small distance, the indicator break is short-circuited by the mercury cup $\mathrm{T}$, and thus the relay circuit remains closed until broken by a contact on the exhaust-valve of the engine. Although somewhat complicated this relay was found to work well, but great care had to be taken that the contacts were all well amalgamated and the mercury clean, otherwise the very small currents in the galvanometer circuit, when a balance is nearly obtained, are entirely broken by any dirt or grease.

To make a determination of the temperature at any required point the contact-maker on the engine-shaft was set, by means of marks on the driving pulley, to make contact at the required position of the piston. An approximate 
balance was then found by putting a suitable resistance in the box and adjusting the position of the slider on the wire. If the temperature had been the same at the same point in the stroke in every working stroke, an accurate balance could have been obtained by shifting the slider till the deflexion of the galvanometer was reduced to zero, but this, however, was not the case, and no attempt in the later work was made to obtain an accurate balance on the bridge-wire. The slider was set in such a position that the galvanometer threw about six sealedivisions to one side of zero, and ten successive throws observed. The slider was then moved until the galvanometer threw about six divisions on the other side, and ten throws observed. By taking the mean of these and interpolating, the true reading on the bridge-wire was obtained.

The gas-pressure was rising towards the end of the experiment from 1.6 to 1.9 inches of water.

Below I give a specimen page of my note-book :-

Resistance in box $2 \cdot 2$ ohms.

Bridge-wire.

\begin{tabular}{|c|c|c|c|}
\hline Gal vanometer-throws at & $\begin{array}{l}500 \\
6 \text { left } \\
5 \\
7 \\
8 \\
7 \\
3 \\
4 \\
10 \\
4 \\
6\end{array}$ & $\begin{array}{l}200 \\
3 \text { right } \\
14 \\
5 \\
16 \\
7 \\
15 \\
24 \\
10 \\
15 \\
25\end{array}$ & $\begin{array}{l}300 \\
2 \text { right } \\
0 \\
10 \\
3 \\
7 \\
12 \\
5 \\
16 \\
17 \\
3\end{array}$ \\
\hline Mean $\ldots . . . .$. & 6.0 left & $13 \cdot 4$ right & 7.5 right \\
\hline
\end{tabular}

Taking the throws at 500 and 300 we obtain, by interpolation from the throws, a bridge-wire reading of 407 , and taking those at 500 and 300 we obtain a reading of 411 .

One division on the galvanometer-scale corresponds to from 15 to 50 divisions of the bridge-wire scale, the former figure being for points towards the end of the stroke, and the latter for points towards the commencement of the stroke of the engine. As a check on this method, I have taken the bridge-wire reading from three points or more instead of two, and have found the results obtained agreed within a few scale-divisions of the bridge-wire. To be accurate, this method presupposes constancy in the testing battery, and in the earlier work considerable trouble was found from the variation of the battery, which was two Leclanche cells. In the later work, both in the determination of the fixed points of the thermometers and for the experiments in the gasengine, a single Daniell cell with an added resistance of 
about 20 ohms was used, and even after many hours' work was found perfectly constant.

There now remains the question, when the resistance of the measuring-wire at any point has been determined, what temperature on the air-scale corresponds to the resistance found. Callendar has shown that if temperature, in degrees Centigrade, be denoted by $t$, and $p t$ denotes what is called the platinum temperature, then

$$
t-p t=\delta\left(\frac{t^{2}}{100^{2}}-\frac{t}{100}\right)
$$

where $\delta$ is a constant which has to be determined for any particular platinum wire; $p t$ is defined as equal to

$$
100 \frac{\mathrm{R}-\mathrm{R}_{0}}{\mathrm{R}_{\mathrm{I}}-\mathrm{R}_{0}}
$$

where $R_{0}$ is the resistance of the wire in melting ice, $R_{1}$ is the resistance of the wire in steam at atmospheric pressure, and $\mathrm{R}$ the resistance of the wire at the temperature $t^{*}$.

As my thermometers consisted of very fine naked wires which were, of necessity, exposed to the erosive action of hightemperature gases, it could not be expected that the fixed points, $i . e$. the resistance in ice and steam, would remain constant after the wire had been in the cylinder for any length of time. Also, owing to the irregular working of the gas- and air-valves, the temperatures reached in the cylinder sometimes far exceeded the mean. When one of these abnormal explosions occurred the wire was sometimes completely fused, and more frequently melted on the surface. These two causes necessitated a frequent determination of the fixed points and also of the value of $\delta$.

Three sizes of measuring-wire were used : they were all about $\frac{3}{4}$ inch long, their diameters being $0.003,0.0025$, and 0.002 inch respectively. The weights of these wires are approximately $0.00182,0.0013$, and 0.00081 gramme respectively, whence, taking the specific heat of platinum as 0.037 , the thermal capacities are $0.0000673,0.0000481$, and 0.00003 gramme-degrees respectively.

I had intended to measure the temperatures by means of all three wires, and from the results obtain a curve giving the lag of the wires; this was, however, not possible owing to want of time and apparatus, but the two finer wires gave temperatures which were nearly equal, while the coarser wire gave results somewhat lower than the two others. This induced me to work with the 0.0025 wire for the bulk of the experiments, as the 0.002 wire had so little mechanical

* Phil. Trans. A, 1887. 
strength that, if an abnormal explosion occurred, it was invariably destroyed.

\section{Calibration of the Thermometers.}

The ice points call for no special remark beyond the fact that, in spite of considerable care in ensuring a mixture of finely crushed ice and water, they were by no means as satisfactory as the steam points. The average resistance of the $0.003,0.0025$, and 0.002 inch diameter wires was $0.3,0.55$, and $0.75 \mathrm{ohm}$ respectively. The steam points were obtained in a double-jacketed hypsometer of the ordinary form, and were corrected for barometric pressure when necessary. When working with these very fine wires, it is imperative to guard against the heating effect of the battery current, otherwise discrepant and inaccurate results are obtained. I have found that the Daniell cell, mentioned above, with resistance in the external circuit gave no appreciable heating unless the observations were made too rapidly. (This of course only applies to the ice and steam points ; when in the engine battery heating is of no importance.)

Two methods were used to obtain the quantity $\delta$. The first method was a comparison of the fine-wire thermometer with a standard Callendar platinum thermometer, both being placed in a tube heated to a high temperature, thus getting a third point on the curve connecting the air and platinum scales.

The standard thermometer consisted of a spiral of platinum wire of a diameter of 0.008 inch wound on a flat plate of mica and enclosed in a porcelain tube 50 centimetres in length, the flat spiral occupying a length of about 7 centimetres from the closed end of the platinum tabe. The fixed points of this thermometer were determined many times in ice and steam, and several times in sulphur and aniline vapours. The values were

$$
\begin{aligned}
\mathrm{R}_{0} & =2: 936 \text { ohms, } \\
\mathrm{R}_{1} & =4 \cdot 080 \text { ohms, } \\
\delta & =1 \cdot 52 .
\end{aligned}
$$

I have not been able to detect any change in the zero, although this thermometer has been raised to a bright red heat several hundred times during the last two years.

For the comparison of the two thermometers an ordinary gas-furnace, such as is used for combustion work, was first used, but was abandoned owing to unequal and unsteady heating. After some trials I adopted a tube-furnace heated with gas-coke; from end to end of the furnace (about 2 feet in length) was placed a cast-iron tube $2 \frac{1}{2}$ inches diameter 
outside and $\frac{1}{2}$ inch thick. This tube could be rotated in bearings, and thus the temperature could be kept steady round the circumference. Inside the cast-iron tube, and independently supported, was a thick copper tube in which were placed the two thermometers for comparison, the fine wire of the steel-tube thermometer nearly touching the porcelain tube of the standard. Owing to the great mass of the metal, the temperature in the inner tube changed very slowly, and by regulating the draught a temperature of $500^{\circ}$ to $600^{\circ} \mathrm{C}$. could easily be obtained. Although this was much better than the gas-furnace, as regards an equal temperature circumferentially, still it could not be assumed that the whole length of the coil of the standard thermometer was at the same temperature as the fine wire on the steel-tube thermometer. During any comparison the standard did not show a variation of more than $2^{\circ} \mathrm{C}$. Unfortunately the fine wire having such a small thermal capacity as compared with the standard, may not be at quite the same temperature as the standard if there is even the slightest change in the temperature. For these reasons the values of $\delta$ as determined by this method are not so satisfactory as might be wished.

In the second method the resistance of the steel-tube thermometer was determined in sulphur vapour as well as in ice and steam. The sulphur was boiled in an apparatus similar to the first form used by Callendar and Griffiths in their determination of the boiling-point of sulphur* * This consisted of a boiler and condenser made of iron tubes. While this method gives very accurate and satisfactory results, it requires extreme care and takes several hours to obtain a steady temperature.

\section{Results of the Experiments.}

It was not until the summer of 1894 that I was able to make any proper experiments with the wires in the cylinder of the gas-engine. I directed my attention at first to the determination of the best speed for the engine, and to find what conditions were necessary to obtain regularity and to ensure that the measuring-wire should follow the temperature of the expanding gases. I found that to obtain regular and perfect combustion of the gases, the water-jacket of the cylinder had to be kept at a temperature of from $50^{\circ}$ to $60^{\circ}$ C., otherwise abnormal explosions were frequent. The speed of the engine was kept constant at about 120 revolutions per minute, and the wire was found to follow the cycle at this speed except at the beginning of the stroke. The number of explosions per minute was from 12 to 14 , each explosion being

$$
\text { * Phil. Trans. A. } 1891 .
$$


followed by about 20 blank strokes. The effect of the thorough "washing-out" of the products of combustion from the cylinder and of the hot cylinder jacket was to produce a temperature in the cylinder as high as, if not higher than, if the engine had been working at full load. The small number of working strokes per minute enabled observations to be made with the galvanometer which would not have been possible at much closer intervals of time. The wear and tear on the measuring-wire was reduced, it being a matter of considerable importance to expose the wire to as few explosions as possible.

In all the following experiments the thermometer measuringwire was placed on the axis of the cylinder and in the centre of the compression space.

Two thermometers were used, both practically of identically the same construction as described above. The results of a number of experiments are given below; I have selected those which I bave reason to believe are the most complete and accurate of the number which I have made. Wherever I bave been able, I have given the constants of the thermometers which were determined before and after the experiments ; where it is not given it is because the wire fused before a re-calibration could be made.

January 1st, 1895.

Thermometer No. 5. Wire 0.003 inch diam. Air temperature $9^{\circ} \mathrm{C}$. Circulating water, $46^{\circ} \mathrm{C}$.

$\mathbf{R}_{0}$ before, $0.324 \mathrm{ohm} . \quad \mathbf{R}_{1}-\mathbf{R}_{0}=0 \cdot 1206 . \quad \delta=1.52$. $\mathbf{R}_{0}$ after, $0.340 \mathrm{obm}$.

\begin{tabular}{|c|c|c|c|}
\hline \multicolumn{4}{|c|}{ First Set. } \\
\hline $\begin{array}{c}\text { Percentage of } \\
\text { stroke. }\end{array}$ & $\begin{array}{c}\text { Observed Resist- } \\
\text { ance, obms. }\end{array}$ & $p t$. & $\begin{array}{c}\text { Temperature on } \\
\text { air-scale. }\end{array}$ \\
\hline 10 & $1 \cdot 476$ & 948 & 1120 \\
20 & $1 \cdot 443$ & 921 & 1085 \\
30 & 1.433 & 913 & 1070 \\
40 & $1 \cdot 362$ & 854 & 990 \\
50 & $1 \cdot 351$ & 845 & 975 \\
60 & $1 \cdot 299$ & 802 & 925 \\
70 & $1 \cdot 286$ & 791 & 900 \\
80 & $1 \cdot 238$ & 751 & 850 \\
\hline \multicolumn{4}{|c|}{ Second Set. } \\
\hline 10 & $1 \cdot 547$ & 1007 & \\
\hline 20 & 1.477 & 949 & 1210 \\
30 & $1 \cdot 466$ & 940 & 1120 \\
40 & $1 \cdot 433$ & 921 & 1085 \\
50 & 1.382 & 871 & 1010 \\
\hline
\end{tabular}


It will be noticed that the second set show considerably higher temperatures than the first; this is due to the fact that the former set were taken just before darkness came on, and the second after the gas-pressure had risen considerably. Owing to this I have generally worked in the morning, when the gas-pressure is generally steady except when there is a sudden fog.

January 2nd, 1895.

Thermometer No. 4 . Wire 0.0025 inch diam.

Circulating water $50^{\circ} \mathrm{C}$.

$\mathrm{R}_{0}$ before, $0.5216 \mathrm{ohm} . \quad \mathrm{R}_{1}$ before, $0.7153 \mathrm{ohm} . \quad \delta$ before, 1.397 .

$\mathbf{R}_{0}$ after, 0.5357 ohm. $\quad \mathbf{R}_{1}$ after, $0.7328 \mathrm{ohm}$. $\delta$ after, 2.09 .

\begin{tabular}{|c|c|c|c|}
$\begin{array}{c}\text { Percentage of } \\
\text { stroke. }\end{array}$ & $\begin{array}{c}\text { Observed Resist. } \\
\text { ance, ohms. }\end{array}$ & $p t$. & $\begin{array}{c}\text { Temp. on air-scale. } \\
\delta=1 \cdot 74 .\end{array}$ \\
\hline 10 & $2 \cdot 474$ & 998 & $\mathbf{1 2 4 5}$ \\
20 & $2 \cdot 455$ & 988 & 1230 \\
30 & $2 \cdot 366$ & 942 & 1150 \\
40 & $2 \cdot 306$ & 912 & 1120 \\
50 & $2 \cdot 248$ & 882 & 1060 \\
60 & $2 \cdot 128$ & 820 & 970 \\
70 & $2 \cdot 108$ & 810 & 950 \\
\hline
\end{tabular}

January 4th, 1895.

Thermometer No. 4. Wire 0.0025 inch diam. Air temperature $10^{\circ} \mathrm{C}$. Circulating water $55^{\circ} \mathrm{C}$.

\begin{tabular}{|c|c|c|c|}
\multicolumn{3}{|c|}{$\mathbf{R}_{0}=0.530 . \quad \mathbf{R}_{1}-\mathbf{R}_{0}=0 \cdot 1971}$. & $\delta=1 \cdot \% 4$. \\
\hline $\begin{array}{c}\text { Percentage of } \\
\text { stroke. }\end{array}$ & $\begin{array}{c}\text { Observed Resist- } \\
\text { ance, ohms. }\end{array}$ & $p t$. & $\begin{array}{c}\text { Temperature } \\
\text { on air-scale. }\end{array}$ \\
\hline Explosion & $2 \cdot 414$ & 956 & 1189 \\
10 & $2 \cdot 483$ & 988 & 1230 \\
20 & $2 \cdot 439$ & 965 & 1195 \\
30 & $2 \cdot 356$ & 923 & 1130 \\
40 & $2 \cdot 338$ & 914 & 1120 \\
50 & $2 \cdot 256$ & 873 & 1040 \\
60 & $2 \cdot 184$ & 836 & 990 \\
70 & $2 \cdot 094$ & 790 & 920 \\
80 & $1 \cdot 960$ & 722 & 830 \\
\hline
\end{tabular}


Thermometer No. 5. Wire 0.003 inch diam.

\begin{tabular}{|c|c|c|c|}
\hline \multicolumn{2}{|c|}{$\mathbf{R}_{\mathbf{0}}=0-332}$. & $\mathbf{R}_{1}-\mathbf{R}_{0}=0.1206$. & $\delta=1.52$. \\
\hline $\begin{array}{c}\text { Percentage of } \\
\text { stroke. }\end{array}$ & $\begin{array}{c}\text { Observed Resist- } \\
\text { ance, ohms. }\end{array}$ & $p t$. & $\begin{array}{c}\text { Temperature } \\
\text { on air-scale. }\end{array}$ \\
\hline Explosion & 1.444 & 919 & 1080 \\
10 & 1.476 & 949 & 1120 \\
20 & 1.451 & 928 & 1095 \\
30 & 1.439 & 918 & 1080 \\
40 & 1.395 & 818 & 1025 \\
50 & 1.392 & 879 & 1020 \\
60 & 1.333 & 830 & 955 \\
70 & 1.268 & 776 & 880 \\
80 & 1.238 & 751 & 855 \\
\hline
\end{tabular}

No further experiments were made with this wire as it clearly did not attain the proper temperature.

January 31st, 1895.

Thermometer No. 4. Wire 0.0025 inch diam. Air temperature $7 \cdot 5^{\circ} \mathrm{C}$. Circulating water $57^{\circ} \mathrm{C}$. $\mathbf{R}_{0}$ before, $0.562 \mathrm{ohm} . \quad \mathbf{R}_{1}-\mathbf{R}_{0}$ before, $02220 \mathrm{ohm} . \quad \delta$ before, 1.90. $\mathbf{R}_{0}$ after, 0.581 ohm. $\quad \mathbf{R}_{\mathbf{1}}-\mathbf{R}_{\mathbf{0}}$ after, 0.227 ohm. $\delta$ after, 1.90 .

\begin{tabular}{|c|c|c|c|}
\hline $\begin{array}{c}\text { Percentage of } \\
\text { stroke. }\end{array}$ & $\begin{array}{c}\text { Observed Resist- } \\
\text { ance, ohms. }\end{array}$ & $p t$. & $\begin{array}{c}\text { Temperature } \\
\text { on air-scale. }\end{array}$ \\
\hline 10 & $2 \cdot 562$ & 893 & 1100 \\
20 & $2 \cdot 595$ & 907 & 1125 \\
30 & $2 \cdot 524$ & 876 & 1080 \\
40 & $2 \cdot 445$ & 840 & 1020 \\
50 & $2 \cdot 360$ & 802 & 960 \\
60 & $2 \cdot 338$ & 792 & 940 \\
70 & $2 \cdot 186$ & 729 & 850 \\
80 & $2 \cdot 151$ & 711 & 825 \\
\hline
\end{tabular}

February 12th, 1895.

Thermometer No. 5. Wire 0.002 inch diam. Air temperature $7^{\circ} \mathrm{C}$. Circulating water $43^{\circ} \mathrm{C}$. $\mathbf{R}_{0}$ before, $0.796 \mathrm{ohm} . \quad \mathbf{R}_{1}-\mathbf{R}_{0}=0.283 \mathrm{ohm}$.

\begin{tabular}{|c|c|c|c|}
\hline $\begin{array}{c}\text { Percentage of } \\
\text { stroke. }\end{array}$ & $\begin{array}{c}\text { Observed Resist. } \\
\text { ance, ohms. }\end{array}$ & $p t$. & $\begin{array}{c}\text { Teup. on air-scale. } \\
\delta=1.22 .\end{array}$ \\
\hline 10 & $3 \cdot 662$ & 1012 & 1160 \\
20 & 3.616 & 996 & 1140 \\
30 & $3 \cdot 477$ & 947 & 1075 \\
40 & 3.352 & 907 & 1020 \\
50 & $3 \cdot 253$ & 868 & 970 \\
60 & $3 \cdot 120$ & 821 & 910 \\
80 & $3 \cdot 071$ & 804 & 890 \\
\hline
\end{tabular}


This wire was destroyed by accident during my absence before a new value of $\delta$ could be determined.

Thermometer No. 4. Wire 0.0025 inch diam.

$\mathbf{R}_{0}=0.592 . \quad \mathbf{R}_{1}-\mathbf{R}_{0}=0.223 . \quad \delta=1.90$.

\begin{tabular}{|c|c|c|c|}
\hline $\begin{array}{c}\text { Percentage of } \\
\text { stroke. }\end{array}$ & $\begin{array}{c}\text { Observed Resist- } \\
\text { ance, ohms. }\end{array}$ & $p t$. & $\begin{array}{c}\text { Temperature } \\
\text { on air-scale. }\end{array}$ \\
\hline Explosion & $2 \cdot 529$ & 878 & 1080 \\
10 & $2 \cdot 580$ & 891 & 1100 \\
20 & $2 \cdot 576$ & 890 & 1100 \\
30 & $2 \cdot 499$ & 855 & 1040 \\
40 & $2 \cdot 459$ & 837 & 1010 \\
\hline
\end{tabular}

The wire partly fused during the observation at 50 per cent. These experiments were made during a period of intense cold, and the indicator diagrams showed the pressures to be lower than usual. The temperatures were lower than those of Jan. 1-5 or March 7-20, otherwise the fine wire on thermometer No. 5 would not have remained intact so long.

\section{March 7 th.}

Thermometer No. 4. Wire 0.0025 inch diam. Air temperature $10^{\circ} \mathrm{C}$. Circulating water $46^{\circ} \mathrm{C}$. $\mathbf{R}_{0}$ before, $0.537 \mathrm{ohm} . \quad \mathbf{R}_{1}-\mathbf{R}_{0}$ before, $0 \cdot 208 . \quad \delta$ before, 1.81 . $R_{0}$ after, $0.551, \quad R_{1}-R_{0}$ after, 0.208. $\delta$ after, 1.75 .

\begin{tabular}{|c|c|c|c|}
\hline $\begin{array}{c}\text { Percentage of } \\
\text { stroke. }\end{array}$ & $\begin{array}{c}\text { Observed Resist- } \\
\text { ance, ohins. }\end{array}$ & $p t$. & $\begin{array}{c}\text { Temp. on air-scale. } \\
\delta=1 \cdot 78 .\end{array}$ \\
\hline 10 & $2 \cdot 437$ & 913 & 1115 \\
20 & $2 \cdot 450$ & 920 & 1120 \\
30 & $2 \cdot 381$ & 886 & 1090 \\
40 & $2 \cdot 333$ & 861 & 1060 \\
50 & $2 \cdot 304$ & 849 & 1015 \\
70 & $2 \cdot 204$ & 801 & 940 \\
80 & $\mathbf{2} 113$ & 757 & 880 \\
\hline
\end{tabular}


March 16th.

Thermometer No. 4. Wire 0.0025 inch diam. Air temperature $13^{\circ} \mathrm{C}$. Circulating water $50^{\circ} \mathrm{C}$.

$\mathrm{R}_{0}$ before, $0.551 \mathrm{obm} . \quad \mathrm{R}_{1}-\mathrm{R}_{0}=0.207$.

$\mathbf{R}_{0}$ after, 0.551 ohm. $\delta$ (determined by sulphur vapour) 1.75 .

\begin{tabular}{|c|c|c|c|}
\hline $\begin{array}{l}\text { Percentage of } \\
\text { stroke. }\end{array}$ & $\begin{array}{l}\text { Observed Resist- } \\
\text { ance, ohms. }\end{array}$ & $p t$ & $\begin{array}{l}\text { Temperature on } \\
\text { air-scale. }\end{array}$ \\
\hline $\begin{array}{l}10 \\
20 \\
30 \\
40 \\
60 \\
70\end{array}$ & $\begin{array}{l}2 \cdot 434 \\
2 \cdot 354 \\
2 \cdot 364 \\
2 \cdot 236 \\
2 \cdot 163 \\
2 \cdot 057\end{array}$ & $\begin{array}{l}909 \\
870 \\
875 \\
833 \\
778 \\
727\end{array}$ & $\begin{array}{r}1100 \\
1045 \\
1050 \\
990 \\
910 \\
840\end{array}$ \\
\hline \multicolumn{4}{|c|}{$\begin{array}{l}\text { I was so doubtful of the second and third points that I } \\
\text { repeated the first three with the results below :- }\end{array}$} \\
\hline $\begin{array}{l}10 \\
20 \\
30\end{array}$ & $\begin{array}{l}2 \cdot 452 \\
2 \cdot 373 \\
2 \cdot 369\end{array}$ & $\begin{array}{l}917 \\
879 \\
877\end{array}$ & $\begin{array}{l}1115 \\
1055 \\
1050\end{array}$ \\
\hline
\end{tabular}

March 20th.

Same thermometer and wire. Air temperature $13^{\circ} \mathrm{C}$. Circulating water $51^{\circ} \mathrm{C}$.

\begin{tabular}{|c|c|c|c|}
\hline $\begin{array}{c}\text { Percentage of } \\
\text { stroke. }\end{array}$ & $\begin{array}{c}\text { Observed Resist- } \\
\text { ance, ohms. }\end{array}$ & $p t$. & $\begin{array}{c}\text { Temperature on } \\
\text { air-scale, }\end{array}$ \\
\hline 10 & $\mathbf{2 . 4 8 1}$ & 931 & 1140 \\
20 & $2 \cdot 403$ & 894 & 1080 \\
30 & $2 \cdot 403$ & 894 & 1080 \\
\hline
\end{tabular}

The temperature was variable throughout this experiment and the wire fused during the observation at 40 per cent.

I consider these experiments to be the most accurate of the whole series.

Towards the end of February I determined to find $\delta$ by means of an observation in sulphur vapour; and as some question had arisen as to the action of the high-temperature gases on the platinum wires, more especially as to the variation of the quantity $\delta$, I gold-soldered a platinum wire 0.002 diameter on No. 5 thermometer, and determined its fixed points and calculated the $\delta$ before this wire was placed in the 
engine. In every other case the wires had been exposed to the action of the cylinder gases for about half an hour before the determination of the fixed points. In this case the wire had only been exposed to the flame of the blowpipe used in the soldering. The fixed points were $R_{0}=0.7596 ; R_{1}=1.0536$; $\frac{\mathrm{R}_{1}}{\mathrm{R}_{0}}=1 \cdot 32 ; \mathrm{R}_{1}-\mathrm{R}_{0}=0.294 ; \delta=2 \cdot 93$.

This value of $\delta$ seemed so high that I repeated the whole of the points without detecting any error in the previous work. The low value of $\frac{R_{1}}{R_{0}}$ together with the high $\delta$ seems to indicate that a gold-platinum alloy formed at the junction of the main lead to the fine wire and on the surface of the latter. The thermometer was then placed in the engine on March 16th and gave the following results :-

$\begin{array}{cccc}\begin{array}{c}\text { Percentage of } \\ \text { stroke. }\end{array} & \begin{array}{c}\text { Observed Resist- } \\ \text { ance, ohms. }\end{array} & p t . & \begin{array}{c}\text { Temperature on } \\ \text { the air-scale. }\end{array} \\ 10 & 3.527 & 948 & 1200\end{array}$

After running in the engine some time the fixed points were re-determined with the results given below:-

$$
\begin{gathered}
\mathrm{R}_{0}=0.786 . \quad \mathrm{R}_{1}=1 \cdot 075 . \quad \mathrm{R}_{1}-\mathrm{R}_{0}=0.289 . \\
\mathrm{R}_{1}=1.37 . \quad \delta=1.95 .
\end{gathered}
$$

From this it will be seen that the action of the gases on the cylinder bad been such as to bring the wire into a normal condition, most probably by sweeping off any alloy which had been formed.

I have plotted the results of the experiments, and the curves are given in Plate II. figs. $5,6, \& 7$, the corresponding pressurevolume curves being given in figs. $8,9, \& 10$. In figs. 5, $6, \& 7$ the horizontal ordinates show the percentage of the stroke, and the vertical ordinates the temperature in degrees C. on the air-scale, the observed points being marked by small circles. I have divided the experiments up into three groups-the first being from Jan. 1 to Jan. 4, the second from Jan. 31 to March 7, and the last from March 16 to March 20. It will be noticed that those of Jan. 1-4 (fig. 5) show a distinct break in the regularity of the curve, the line falling but little between the 3rd and 4 th points on the 0.0025 wire and between the 4 ith and 5 th points on the 0.003 wire, instead of falling regularly throughout as would have been expected. The curves of the second group of experiments (fig. 6) show no trace of irregularity; while those of the third group (fig. 7) 
show a strongly marked variation between the 2 nd and 3rd points. Several explanations of this singularity have suggested themselves to me, but I do not consider them to come within the scope of this paper. I hope to make further experiments bearing on this matter, and to obtain more data on the subject. The results of the experiments of Jan. 31 to March 7 are chiefly interesting as showing the close concordance of temperatures registered by wires of such different thermal capacity, especially when it is remembered that the source of heat used was a very variable one, the pressures, as shown on the indicator cards, varying from day to day, and also during the day, owing to the varying gas-pressure and quality.

1 would also point out that a difference of 100 degrees shown on the thermometers corresponds to a distance of about $\frac{1}{12}$ inch on the indicator cards.

In conclusion I must express my thanks to Messrs. Johnson and Matthey for the trouble they have taken in drawing down the wires, several of which were of special diameters. I should have been quite unable to carry out costly experiments of this kind had it not been for the liberality of my brother, $\mathrm{Mr}$. $\mathrm{H}$. R.J. Burstall, who has provided me with the necessary funds. The apparatus has been designed and carried out in conjunction with him; and I wish to express my sincere indebtedness to him for his many suggestions, which have made these experiments possible.

XXIV. On the Constituents of Cleveite Gas. By Professors C. Runge and F. Paschen, of Hannover*.

QINCE our communication about the Spectrum of Heliumt, $S$ we have succeeded in constructing materially better Geissler tubes, which show only traces of impurities, and which emit the light of the gas itself with the greatest brightness. With these new tubes it has not only been possible to explore the infra-red portion of the spectrum as far as $10 \mu$ with the bolometer, and to discover both of the first members of the two series which, according to our formula, should have wave-lengths of about $1.11 \mu$ and $2.03 \mu$, and which have been found at the positions $1 \cdot 120 \mu$ and $2 \cdot 040 \mu$, but, besides, the connexion of the other lines of the spectrum comes out with full distinctness.

* Translated by Dr. G. Johnstone Stoney, F.R.S., from the Proceedings of the Berlin Academy of July 11, 1895.

$\dagger$ Proceedings of the Berlin Academy of June 20, 1895.

P'hil. Mag. S. 5. Vol. 40. No. 244. Sept.1895. X X 